\title{
Development of bilateral tension pneumothorax under anesthesia in a Boerhaave's syndrome patient -a case report-
}

\author{
Mi Kyung Oh, Woo Jae Jeon, Sang Yun Cho, Yong Deok Kwon, and \\ Kyoung Hun Kim \\ Department of Anesthesiology and Pain Medicine, Hanyang University Guri Hospital, Guri, Korea
}

\begin{abstract}
A 33-year-old male visited the emergency room with abdominal pain which developed after a vomiting episode. Based on the pneumomediastinum findings from a chest radiograph and a contrast-enhanced chest and abdominal computed tomography scan, the patient was diagnosed with Boerhaave's syndrome. Preoperative radiologic findings showed no pneumothorax or pleural effusion. Once anesthesia was administered, the patient developed near complete cardiopulmonary collapse due to a bilateral tension pneumothorax, which was treated by bilateral thoracentesis, followed by chest tube insertion. Despite a left side rupture, the damaged right lung was unable to overcome single right ventilation, so the surgery was completed via right thoracotomy. The ruptured site was treated, and the patient was transferred to the intensive care unit. We discuss the anesthetic implications of this disease and how to prevent fatal complications.
\end{abstract}

Key Words: Boerhaave syndrome, General anesthesia, Positive-pressure respiration, Pneumothorax.

Hermann Boerhaave described spontaneous esophageal perforation for the first time in 1724 , leading to the coining of the term "Boerhaave's syndrome". Its most common trigger is vomiting, which often results in a rupture in the left distal esophageal area [1]. According to Meckler, Boerhaave's syndrome is identifiable by a typical triad of symptoms, which including vomiting, epigastric and chest pain, and subcutaneous

Corresponding author: Sang Yun Cho, M.D., Ph.D.

Department of Anesthesiology and Pain Medicine, Hanyang University Guri Hospital, 153, Gyeongchun-ro, Guri 11923, Korea

Tel: 82-31-560-2394, Fax: 82-31-563-1731

E-mail: chosy@hanyang.ac.kr

ORCID: http://orcid.org/0000-0002-6593-1960

Received: July 24, 2014.

Revised: 1st, October 10, 2014; 2nd, December 29, 2014;

3rd, February 3, 2015.

Accepted: February 16, 2015.

Korean J Anesthesiol 2016 April 69(2): 175-180

http://dx.doi.org/10.4097/kjae.2016.69.2.175 emphysema. However, these symptoms usually do not develop simultaneously, thus, diagnosis is often delayed [2]. Mortality and morbidity rates are very high - the death rate among treated patients is between $20-40 \%$; the mortality rate of non-treated patients is virtually $100 \%$ [1]. The most critical factors for determining prognosis are the level of mediastinal invasion and the degree of damage to the mediastinal pleura. When the mediastinal pleura are damaged, pulmonary symptoms, such as pleural effusion or pneumothorax may occur, as well as shock or sepsis $[1,2]$. Herein we report a case of esophageal rupture with serious complications under anesthesia along with a literature review.

\section{Case Report}

A 33-year-old male who was $183 \mathrm{~cm}$ tall and weighed $94 \mathrm{~kg}$ visited the emergency room (ER) of our hospital with severe abdominal pain as his chief complaint. The abdominal pain developed after he vomited the night before at 22:00, and the pain continued even after he had breakfast the day after his hospital visit. He had visited another hospital before admission to our

(c) This is an open-access article distributed under the terms of the Creative Commons Attribution Non-Commercial License (http://creativecommons.org/ licenses/by-nc/4.0/), which permits unrestricted non-commercial use, distribution, and reproduction in any medium, provided the original work is properly cited. 
hospital, but his pain did not diminish, and he experienced minor mental deterioration. He was transferred to the ER of our hospital with suspected ileus.

Upon arrival to the ER, his vital signs were as follows: blood pressure (BP) 105/63 mmHg, heart rate (HR) 69 beats/min, peripheral oxygen saturation $\left(\mathrm{SpO}_{2}\right) 99 \%$, respiratory rate $(\mathrm{RR})$ $20 \mathrm{rates} / \mathrm{min}$, and body temperature $36.9^{\circ} \mathrm{C}$. The arterial blood gas analysis (ABGA) conducted in room air revealed the following: $\mathrm{pH} 7.64$, arterial $\mathrm{CO}_{2}$ partial pressure $\left(\mathrm{PaCO}_{2}\right) 25.8 \mathrm{mmHg}$, arterial $\mathrm{O}_{2}$ partial pressure $\left(\mathrm{PaO}_{2}\right) 111.1 \mathrm{mmHg}$, and base excess (BE) $8.3 \mathrm{mmol} / \mathrm{L}$. Also, a chest radiograph was taken (Fig. 1). Immediately after undergoing the chest and abdominal CT, the patient's BP reached $83 / 66 \mathrm{mmHg}$, and his HR increased from 70 beats/min to 116 beats/min. Ten minutes after an intravenous administration of $100 \mathrm{ml}$ of crystalloid fluids, the patient's BP reached 124/88 $\mathrm{mmHg}$. A severe increase in stomach volume was observed through CT, due to stricture in the gastric pylorus and duodenum. An attempted insertion of a nasogastric tube was unsuccessful. A chest radiograph and before-and-after contrast-enhanced CT suggested pneumomediastinum, a possibility that was heightened by evidence of an esophageal rupture. After making the diagnosis of esophageal rupture, a right internal jugular vein catheterization was performed by the surgeon. After catheterization, the patient's BP was measured to be $84 / 44$ $\mathrm{mmHg}$ and his HR was 113 beats/min. An additional $300 \mathrm{ml}$ of crystalloid solution was administered intravenously, and $2 \mathrm{~L} / \mathrm{min}$ of oxygen was administered through a nasal cannula. The $\mathrm{SpO}_{2}$ was $97 \%$.

About 24 hours after the vomiting episode, at which time esophageal rupture was suspected to have occurred, the patient was moved to the operating room. His fasting time was 12 hours.

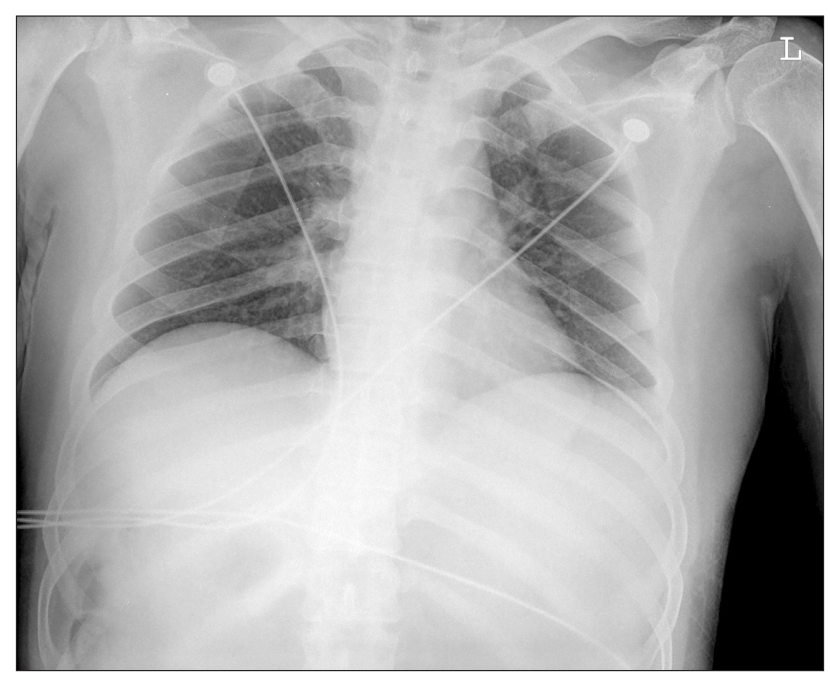

Fig. 1. Preoperative chest AP shows pneumomediastinum around the shadow of the descending aorta.
In preoperative blood tests, increased levels were observed for the following measures: blood urea nitrogen $32 \mathrm{mg} / \mathrm{dl}$, creatine $2.2 \mathrm{mg} / \mathrm{dl}$, and white blood cell 12,400 / $\mathrm{mm}^{3}$. The patient's consciousness was clear. Before anesthesia, his BP was 80/50 $\mathrm{mmHg}$, HR was 125 beats/min, and $\mathrm{SpO}_{2}$ was $94 \%$ on a fraction of inspired oxygen $\left(\mathrm{FIO}_{2}\right)$ 0.21. After preoxygenation with $100 \%$ oxygen for about 1 minute, his $\mathrm{SpO}_{2}$ reached 99\%. General anesthesia was induced using a facial mask with $100 \%$ oxygen with an instillation of $15 \mathrm{mg}$ of etomidate and $20 \mathrm{mg}$ of cisatracurium. Manual ventilation was performed with a tidal volume (TV) of 400-500 ml, RR of 15 rates/min, peak inspiratory pressure (PIP) of 15-25 $\mathrm{cmH}_{2} \mathrm{O}$, and end-tidal $\mathrm{CO}_{2}$ partial pressure $\left(\mathrm{ETCO}_{2}\right)$ of $30-40 \mathrm{mmHg}$. After 90 seconds, an endotracheal intubation was performed using a $37 \mathrm{Fr}$ left-sided double-lumen tube (DLT) (Mallinckrodt ${ }^{\mathrm{TM}}$, Covidien, Ireland). Breath sounds from both lungs for both the right and left ventilation were confirmed through auscultation and chest wall movement. The proper location of the tube was confirmed using a flexible fiberoptic bronchoscope. For mechanical ventilation, the pressure control ventilation (PCV) mode started with a PIP of $20 \mathrm{cmH}_{2} \mathrm{O}$, positive end expiratory pressure (PEEP) of $0 \mathrm{cmH}_{2} \mathrm{O}$, a $\mathrm{RR}$ of 12 rates/min, TV of $500-600 \mathrm{ml}$, and $\mathrm{FIO}_{2}$ of 1.0 . Anesthesia was maintained with desflurane 2 vol\% at $\mathrm{FIO}_{2} 1.0$ and a continuous intravenous infusion of dopamine $5 \mu \mathrm{g} / \mathrm{kg} / \mathrm{min}$ was started. The patient was maintained at a systolic BP of 90-110 $\mathrm{mmHg}$, a diastolic of BP $50-70 \mathrm{mmHg}$, a HR of $110-120$ beats/min, a central venous pressure of $14-16 \mathrm{cmH}_{2} \mathrm{O}$, a ETCO $\mathrm{ET}_{2}$ of $30-35 \mathrm{mmHg}$, a bispectral index score (BIS) of 30-40, and $\mathrm{SpO}_{2}$ of $99 \%$.

In the right lateral position for the left thoracotomy, single right lung ventilation was conducted. At that time, the PCV mode was maintained with a PIP of $20 \mathrm{cmH}_{2} \mathrm{O}$, a PEEP of 0 $\mathrm{cmH}_{2} \mathrm{O}, \mathrm{RR}$ of 15 rates/min, and TV of $300-400 \mathrm{ml}$. The ABGA with a $\mathrm{FIO}_{2} 1.0$ showed a $\mathrm{pH}$ of $7.439, \mathrm{PaCO}_{2}$ of $36.5 \mathrm{mmHg}$, $\mathrm{PaO}_{2}$ of $154.3 \mathrm{mmHg}$, and $\mathrm{BE}$ of $1.3 \mathrm{mmol} / \mathrm{L}$. After the first 10 minutes of one-lung ventilation, during the surgical preparation process, including disinfection and application of sterilized cloth pieces, $\mathrm{SpO}_{2}$ levels were gradually decreased. After it was confirmed that $\mathrm{FIO}_{2}$ was exactly 1.0, manual ventilation was performed. The location of the tube was checked using a flexible fiberoptic bronchoscope, and it was confirmed to have been in the proper position. Inhalation of volatile anesthetics was stopped. The $\mathrm{SpO}_{2}$ dropped to $80 \%$, so two-lung ventilation was conducted, but the $\mathrm{SpO}_{2}$ level did not improve. During auscultation, both breath sounds slightly decreased. Three minutes after the onset of desaturation, after consultating with a thoracic surgeon, the patient was moved to the supine position immediately. However, the $\mathrm{SpO}_{2}$ dropped even further, to $70 \%$, and the bilateral breath sounds remained low. The proper position of the DLT was confirmed again, but the desaturation state persisted. The DLT was replaced with a single-lumen tube. Because 
manual ventilation was maintained throughout the desaturation event, it was not possible to check the airway pressure precisely. TV was maintained at $300-400 \mathrm{ml}$, and $\mathrm{ETCO}_{2}$ was revealed to be $25-35 \mathrm{mmHg}$. Within a minute, the $\mathrm{SpO}_{2}$ dropped to $50 \%$, $\mathrm{ETCO}_{2}$ to $10 \mathrm{mmHg}$, HR below 40 beats/min and systolic BP dropped to $50 \mathrm{mmHg}$. Cardiopulmonary resuscitation (CPR) was performed immediately by a thoracic surgeon who performed thoracic compressions. At the same time, $1 \mathrm{mg}$ of epinephrine was injected twice. Because bilateral breath sounds disappeared, the possibility of bilateral tension pneumothorax was strongly suspected. Right after the CPR was started, a 20 gauge angiocatheter was inserted into the left second mid-clavicle, and it was confirmed that there was a leakage of at least $50 \mathrm{ml}$ of air by syringe aspiration. In the right second mid-clavicle, the same 20 gauge angiocatheter was inserted, and a leakage of air with a foul smelling brown liquid through the angiocatheter was confirmed. The patient's $\mathrm{SpO}_{2}$ gradually increased to over $90 \%$ in just a few seconds. Within one minute of the start of CPR, the patient's HR improved to 70-80 beats/min, his systolic BP to $100-120 \mathrm{mmHg}$, and his $\mathrm{SpO}_{2}$ to $94-95 \%$. During the CPR process, the patient's BIS score never dropped below 10. As the patient's condition began to stabilize, CPR was terminated. The total duration of the CPR process was not longer than a minute. An emergency chest radiograph was taken to detail the damage (Fig. 2). The damage in the right side was considered more serious than in the left, so a chest tube was inserted into the right chest first, and then into the left. Breath sounds were recovered from both lungs. The patient's $\mathrm{SpO}_{2}$ eventually reached $100 \%$ on $\mathrm{FIO}_{2}$ 1.0.

Because there was more than $800 \mathrm{ml}$ of stomach contents

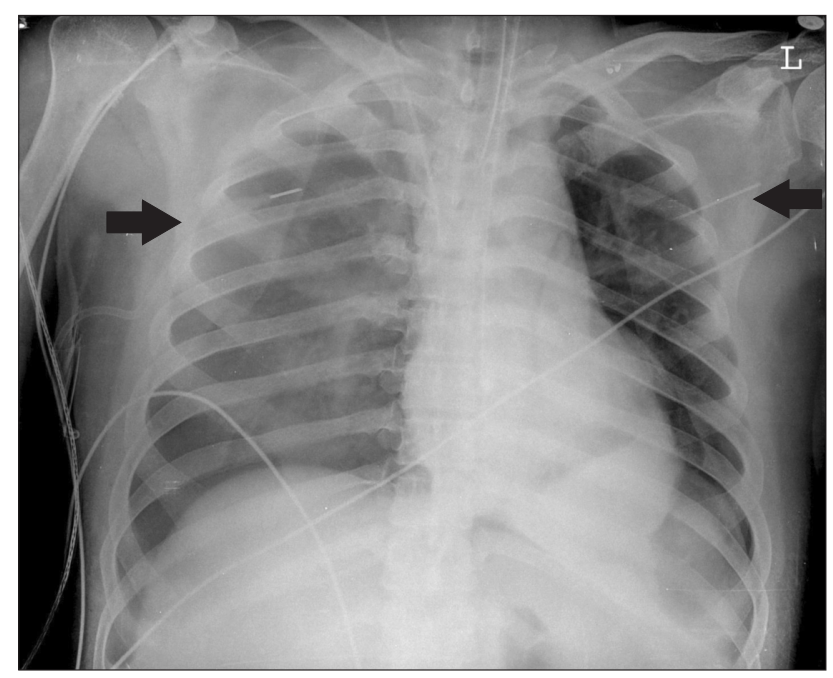

Fig. 2. Chest radiograph taken at in the operating room shows haziness and pleural effusion in the right lung. The arrows indicate the angiocatheter inserted into both lungs for air release. gushing out and massive air constantly leaking from the right chest tube, it was strongly suspected that severe lung parenchymal damage had occurred. It was decided to change from the originally planned right-lung ventilation to left-lung ventilation. The DLT was inserted again. During the right thoracotomy, more than $500 \mathrm{ml}$ of stomach contents was suctioned out from the right lung, and we continuously irrigated the lung. In the surgical visual field, an extensive chemical burn from the gastric juice was observed in the dependent area of the lung (Fig. 3).

Despite the fact that the esophageal rupture occurred on the left side, a right thoracotomy was performed, which resulted in a poor visual field and extended surgical time. The ruptures in the epiphrenic esophagus and the subphrenic stomach were about $2 \mathrm{~cm}$ long each. The total time required for performing distal esophagectomy, esophagogastrostomy, and feeding jejunostomy was 11 hours. The total amount of fluids administered during surgery was $4500 \mathrm{ml}$ of colloid solution, $4050 \mathrm{ml}$ of crystalloid solution, and 2 pints of packed red blood cells. The estimated blood loss was $1000 \mathrm{ml}$ and the urine output was $1700 \mathrm{ml}$. At the end of the surgery, the ABGA with an $\mathrm{FIO}_{2} 1.0$ showed a $\mathrm{pH}$ of $7.429, \mathrm{PaCO}_{2}$ of $31.3 \mathrm{mmHg}, \mathrm{PaO}_{2}$ of $367.7 \mathrm{mmHg}$, and $\mathrm{BE}$ of $-2.2 \mathrm{mmol} / \mathrm{L}$. After the surgery, the tube was replaced with a single-lumen tube, and the patient was transferred to the intensive care unit (ICU).

On chest radiography conducted at the ICU, no pulmonary edema was observed (Fig. 4). Mechanical ventilation care was performed in the assisted control mode, maintained at a pressure of $14 \mathrm{cmH}_{2} \mathrm{O}$, a RR of 12 breaths/min, a PEEP of $6 \mathrm{cmH}_{2} \mathrm{O}$, and $\mathrm{FIO}_{2}$ of 0.6. A continuous intravenous infusion of fentanyl was maintained at the rate of $20-40 \mu \mathrm{g} / \mathrm{h}$ for sedation and pain

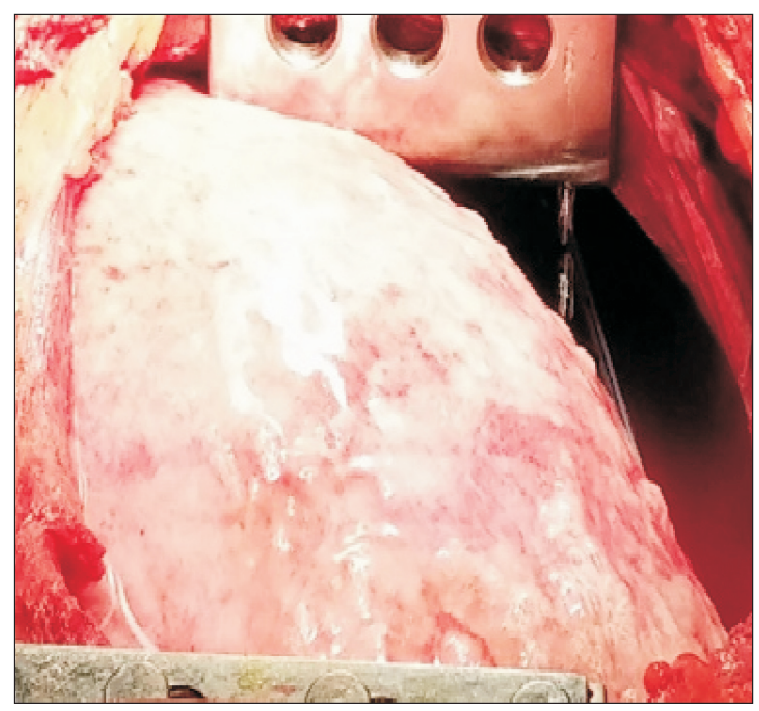

Fig. 3. Lung, as seen in the surgical visual field: An extensive chemical burn is observed. 


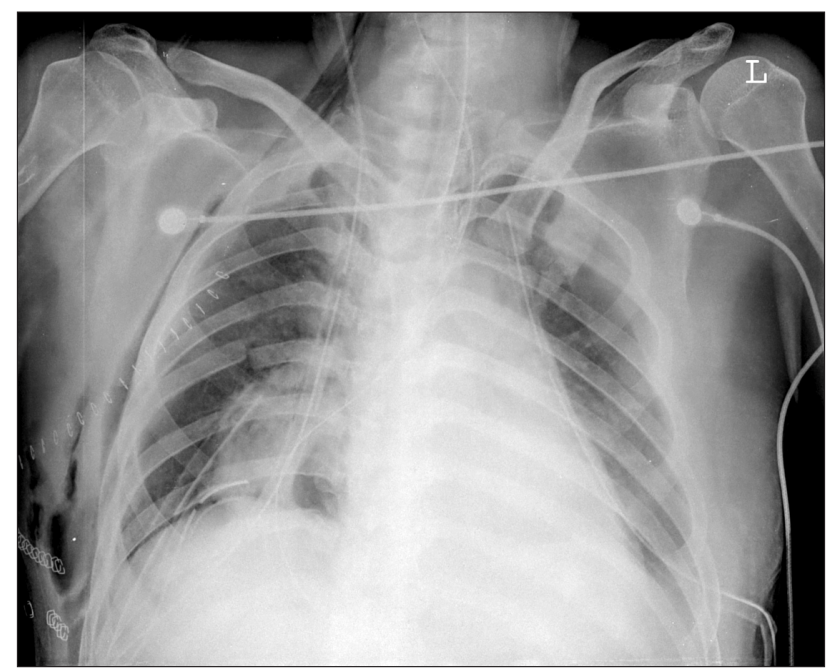

Fig. 4. Postoperative state after an esophageal rupture without any significant lung parenchyma lesions.

control. Two hours after the operation, the ABGA showed a $\mathrm{pH}$ of 7.43, a $\mathrm{PaCO}_{2}$ of $31 \mathrm{mmHg}$, a $\mathrm{PaO}_{2}$ of $211 \mathrm{mmHg}$, and a $\mathrm{BE}$ of $-2 \mathrm{mmol} / \mathrm{L}$. The patient's mental status was drowsy due to sedation, and otherwise unremarkable.

One day after the operation, mechanical ventilation was maintained as before, but the $\mathrm{FIO}_{2}$ was decreased to 0.4. The ABGA showed a $\mathrm{pH}$ of 7.39 , a $\mathrm{PaCO}_{2}$ of $35 \mathrm{mmHg}$, a $\mathrm{PaO}_{2}$ of $169 \mathrm{mmHg}$, and a $\mathrm{BE}$ of $-2.0 \mathrm{mmol} / \mathrm{L}$. The patient's vital signs were stable, and the $\mathrm{SpO}_{2}$ was $99 \%$ at $\mathrm{FIO}_{2} 0.4$.

Five days after the surgery, mechanical ventilation was stopped and a T-piece was applied at $\mathrm{FIO}_{2}$ 0.35-0.50.

Seven days after surgery, the patient was extubated and, on the eighth day, he was moved to a general ward. His vital signs were stable, mental status was alert, and $\mathrm{SpO}_{2}$ was $97 \%$ at $3 \mathrm{~L} / \mathrm{min}$ of oxygen administered through a nasal cannula.

Eleven days after the surgery, the left-side chest tube was removed. Twenty-five days after the surgery, the right-side chest tube was also removed. Thirty-two days after the surgery, the patient was discharged without complications.

\section{Discussion}

Boerhaave's syndrome's early symptoms include epigastric and chest pain, tachycardia, perspiration, pyrexia, hypotension, and cervical subcutaneous emphysema. In cases of intraabdominal esophageal rupture, peritonitis symptoms are also observed. Meckler's classic triad of symptoms include vomiting, epigastric and chest pain, and subcutaneous emphysema; however, most Boerhaave's syndrome patients do not display all the typical symptoms simultaneously. Therefore, only about $21 \%$ of cases get diagnosed within 12 hours of the rupture develop- ment, increasing the mortality rate. It is difficult to differentially diagnose early-stage cases of Boerhaave's syndrome from acute myocardial infarction, pancreatitis, rupture in other abdominal organs, spontaneous pneumothorax, pulmonary thromboembolism, or aortic dissection, thus, subtle symptoms or new diagnostic features are very important to identify [2-4].

The major diagnostic tool for Boerhaave's syndrome is the chest radiograph, which has $88 \%$ sensitivity and helps diagnose pneumomediastinum, subcutaneous emphysema, pneumothorax, and pleural effusion. Additionally, esophagography and CT with a contrast agent can be used for the definitive diagnosis of Boerhaave's syndrome [5].

The most important factor for determining prognosis after an esophageal rupture is the severity of the mediastinal inflammation. The more severe this symptom is, the greater the deterioration in cardiopulmonary function, and the higher the risk for shock. Mediastinal inflammation is a secondary development caused by the influx of gastric juice, digestive enzymes, food, and bacteria. The mediastinal pleura rupture simultaneously with the rupture of the esophagus, or after digesting the stomach contents. Within 12 hours after the esophageal rupture, the mediastinal pleura are usually not ruptured, and the patient may have normal vital signs $[1,2,6,7]$. Accordingly, the prognosis is favorable if the operation is performed during this time. Esophageal rupture patients usually complain of abdominal symptoms soon after the rupture; after some time, their chief complaint is usually chest pain rather than abdominal pain. When the mediastinal pleura become ruptured, pleural effusion develops, and negative pressure pushes the stomach contents and gastric juice into the thoracic cavity. Consequently, inflammation increases, and shock, sepsis, and other respiratory problems, such as pleural effusion, pneumothorax, hydrothorax, and tension pneumothorax can develop $[1,2,6]$.

Preoperative bilateral damage in the mediastinal pleura were recognized due to the development of bilateral tension pneumothorax in our patient. A direct channel between the esophagus and the pleural cavity was made. The damaged pleura were thought to have played the role of a pseudo-valve that contained air during inhalation to facilitate the advancement of the pneumothorax $[2,7,8]$. Chemical burns in the lung-dependent area caused by an influx of gastric juice were observed later through the surgical visual field. This implied that lung damage had begun before induction.

Because there were no specific findings other than pneumomediastinum from the preoperative chest images, we determined then that the pulmonary complications were not fully advanced. But various preoperative findings suggested the possibility that the mediastinal pleura might have already ruptured.

The grounds for suspecting the mediastinal pleura rupture are as follows. Our patient's rupture-to-operation time was 24 
hours, which was far longer than 12 hours, a duration commonly considered to as the average for the mediastinal pleura to be fully digested by gastric juice. Even though the patient did not complain of chest pain or dyspnea, his $\mathrm{PaCO}_{2}$ level reached $25.8 \mathrm{mmHg}$, which indicated hyperventilation. Considering the increase in the patient's blood urea nitrogen and creatine level, he might also have been experiencing dehydration. The patient's vital signs changed continuously, his blood pressure and $\mathrm{SpO}_{2}$ level decreased and heart rate increased, especially after the first CT scan and after the right central venous catheterization. This could have indicated that the patient was experiencing systemic inflammatory and shock reactions.

The mechanism of the development of the tension pneumothorax in our case is possibly due to the positive pressure ventilation during manual ventilation prior to intubation or during mechanical ventilation [6].

We should have suspected the possibility of pneumothorax and considered the chest tube placement prior to the initiation of positive pressure ventilation in this patient. The appropriate management of occult pneumothorax, defined as a pneumothorax on CT, with positive pressure ventilation still controversial [9]. Tension pneumothorax in ventilated patients has been reported to have a mortality rate of up to $91 \%$ in one study [10]. Prophylactic pleural drainage can prevent a pneumothorax, but it has also been reported to have caused complications such as bleeding, infection, and malposition [9].

Prophylactic chest tube placement in esophageal rupture patients can serve as a fast drainage passage for stomach contents in the case of failed nasogastric tube insertion. Nasogastric tube insertion is usually not recommended because of the high risk of worsening the esophageal rupture [2]; however, in this case, a massive amount of stomach contents flowed into the right lung after the body position was changed to the right lateral position, which resulted in more serious lung damage in the right side than in the left. Consequently, the scheduled left thoracotomy could not be performed. The esophageal rupture in the left side caused difficulties for visualizing the surgical field and for performing the surgery.

When tension pneumothorax occurs, the missed diagnosis is more probable, than if mechanical ventilation or cardiopulmonary resuscitation had been performed [11]. In our case, tension pneumothorax had not been considered as the first probable cause of desaturation since it is such a rarity, and its bilateral occurrence is even less frequent. Other frequently occurring causes such as DLT malpositioning, tube failure, or the ventilation effect caused by the body position, were considered instead. Tube failure can be caused by problems such as kinking, obstruction, and defection.

The continuous deterioration in the patient's condition and the loss of breath sounds were consistent with a tension pneumothorax [12]. Close cooperation between the anesthesia team and the surgeon made it possible to make prompt diagnostic and treatment decisions, resulting in the completion of anesthesia and the procedure without any serious complications.

Only a few cases of tension pneumothorax that developed in Boerhaave's syndrome patients during anesthesia have been reported so far in the literature.

This case may offer anesthesiologists a good opportunity to familiarize themselves with an uncommon disease, and we think that prediction and preparation for unexpected situations will provide the patient with a better opportunity for a good prognosis.

\section{References}

1. Curci JJ, Horman MJ. Boerhaave's syndrome: the importance of early diagnosis and treatment. Ann Surg 1976; 183: 401-8.

2. Pandey CK, Bose N, Dash NR, Singh N, Saxena R. Perioperative management of a patient presenting with a spontaneously ruptured esophagus. Can J Anaesth 2002; 49: 409-12.

3. Baric A. Oesophageal rupture in a patient with postoperative nausea and vomiting. Anaesth Intensive Care 2000; 28: 325-7.

4. Jagminas L, Silverman RA. Boerhaave's syndrome presenting with abdominal pain and right hydropneumothorax. Am J Emerg Med 1996; 14: 53-6.

5. Onyeka WO, Booth SJ. Boerhaave's syndrome presenting as tension pneumothorax. J Accid Emerg Med 1999; 16: 235-6.

6. Patel MS, Chakraborty PU. A case of Boerhaave's syndrome presenting after a trial of non-invasive ventilation. Med Princ Pract 2009; 18: $155-8$.

7. Venø S, Eckardt J. Boerhaave's syndrome and tension pneumothorax secondary to Norovirus induced forceful emesis. J Thorac Dis 2013; 5: E38-40.

8. Matsumoto MA, Rockoff SD, Aaron BL. Tension pyopneumothorax. Rare presentation of ruptured Barrett's esophagus. Chest 1993; 103: 1604-6.

9. Kirkpatrick AW, Rizoli S, Ouellet JF, Roberts DJ, Sirois M, Ball CG, et al. Occult pneumothoraces in critical care: a prospective multicenter randomized controlled trial of pleural drainage for mechanically ventilated trauma patients with occult pneumothoraces. J Trauma Acute Care Surg 2013; 74: 747-54. 
10. Chen KY, Jerng JS, Liao WY, Ding LW, Kuo LC, Wang JY, et al. Pneumothorax in the ICU: patient outcomes and prognostic factors. Chest 2002; 122: 678-83.

11. Leigh-Smith S, Harris T. Tension pneumothorax--time for a re-think? Emerg Med J 2005; 22: 8-16.

12. Watts BL, Howell MA. Tension pneumothorax: a difficult diagnosis. Emerg Med J 2001; 18: 319-20. 